\section{Fentanyl pretreatment attenuates the haemodynamic response to sudden inhalation of $5 \%$ isoflurane}

Hiroyuki Kinoshita MD, Hiroya Wakamatsu MD,

Yasuaki Taira MD, Kazuyoshi Ishida MD,

Akitomo Yonei MD
High concentrations of inhaled isoflurane can increase heart rate and/or arterial pressure. The purpose of this study was to determine whether fentanyl has a prophylactic effect on the isoflurane-induced circulatory response in adult patients. Thirty patients due to undergo elective surgery were randomly allocated to one of three groups of ten patients. Prior to surgery, one group inhaled $2.5 \%$ isoflurane, another inhaled $5.0 \%$ isoflurane, and the third group inhaled $5.0 \%$ isoflurane and were given fentanyl $2 \mu \mathrm{g} \cdot \mathrm{kg}^{-1} \dot{\text { iv }}$ two minutes before induction of anaesthesia. Anaesthesia was induced with thiamylal followed by vecuronium. The lungs were ventilated with $100 \%$ oxygen and either $2.5 \%$ or $5.0 \%$ isoflurane via face mask. Ventilation was continued for five minutes. Heart rate (HR) and mean arterial pressure (MAP) were recorded at two minutes before induction of anaesthesia (baseline), immediately before the induction of anaesthesia, and at three and five minutes afier induction, respectively. It was found that $5.0 \%$ isoflurane caused an increase in HR compared with baseline $(P<0.01)$ and with the $2.5 \%$ isoflurane $(P<0.05): 2.5 \%$ isoflurane did not elicit this response. An increase was also noted in MAP, compared with the $2.5 \%$ isoflurane $(P<0.01): 2.5 \%$ isoflurane did not elicit this increase. Fentanyl pretreatment attenuated the increases in HR and in MAP that occurred with $5.0 \%$ isoflurane $(P<0.01)$. These results suggest that fentanyl attenuates the enhancement of both $H R$ and MAP from face mask inhalation of a high concentration of isoflurane.

\section{Key words}

ANAESTHETICS: isoflurane, fentanyl;

HEART: hypertension, tachycardia.

From the Department of Anesthesia, Kurashiki Central Hospital, Miwa 1-1-1, Kurashiki, Okayama 710, Japan.

Address correspondence to: Dr. Akitomo Yonei, Department of Anesthesia, Kurashiki Central Hospital, Miwa 1-1-1, Kurashiki, Okayama 710, Japan.

Accepted for publication 22nd November, 1994.
Linhalation de fortes concentrations d'soflurane peut augmenter la fréquence cardiaque et la pression artérielle. Cette étude a pour objectif de déterminer si le fentanyl protège le sujet adulte de ces réponses circulatoires induites par lisoflurane. Trente patients programmés pour une chirurgie non urgente sont répartis au hasard en trois groupes égaux. Avant la chirurgie, un groupe inspire de lisoflurane à $2,5 \%$, le deuxième de lisoflurane à $5 \%$, et le troisième de lisoflurane à $5 \%$ et reçoit du fentanyl $2 \mu \mathrm{g} \cdot \mathrm{kg}^{-1}$ iv dewx minutes avant linduction de l'anesthésie. L'anesthésie est induite avec du thiamylal suivi de vécuronium au masque facial. Les poumons sont ventilés avec de l'oxygène à $100 \%$ associé à lissoflurane $2,5 \%$ ou $5 \%$. La ventilation est continuée pendant cinq minutes. La fréquence cardiaque $(F C)$ et la pression artérielle moyenne (PAM) sont enregistrées deux minutes avant linduction (mesure initiale), immédiatement avant linduction de l'anesthésie et trois et cinq minutes après l'induction. Les résultats montrent que lisoflurane à $5 \%$ produit une augmentation de FC comparativement à la mesure initiale $(P<0,01)$ : mais que lisoflurane à $2,5 \%$ ne provoque pas cette réponse $(P<0,05)$. Une augmentation de la MAP est aussi notée comparativement à lisoflurane $2,5 \%(P<0,01)$ :l isoflurane $2,5 \%$ ne provoque pas cette augmentation. Le prétraitement au fentanyl diminue l'augmentation de la FC et de la MAP qui survient avec lisoflurane $5 \%(P<0,01)$. Ces résultats suggèrent que le fentanyl atténue l'augmentation à la fois de la FC et de la MAP pendant l'administration au masque de concentrations élevées d'soflurane.

Abrupt inhalation of high concentrations of isoflurane, whether via face mask, ${ }^{1,2}$ or endotracheal tube, ${ }^{3,4}$ can cause increases in heart rate and in arterial pressure. Although the mechanisms of these circulatory responses are not known, it has been suggested that stimulation of the nasal mucosa ${ }^{1,5}$ and/or sensory nerve endings in the lung ${ }^{4}$ by a pungent volatile anaesthetic might be the cause. Moreover, it was found that isoflurane-induced tachycar- 
dia and increased arterial pressures occur concurrently with enhancement of the plasma norepinephrine concentration. 3,4

Episodes of tachycardia and increases in arterial pressure affect ischaemic heart disease patients adversely, since they aggravate the myocardial oxygen demand and decrease the myocardial oxygen supply. However, a reliable prophylactic regimen that ameliorates these responses has yet to be found. Fentanyl, a commonly used opioid, acts on the central nervous system, possesses vagotonic effects, ${ }^{6,7}$ and decreases plasma catecholamine concentrations, which might indicate a reduction in sympathetic nerve activity. ${ }^{89}$ This suggests that fentanyl may have a prophylactic effect on high concentration isoflurane-induced circulatory responses. Therefore, we investigated the effect of fentanyl pretreatment on the isoflurane-induced responses of heart rate and arterial pressure during induction of anaesthesia.

\section{Methods}

On receiving approval for this study by the hospital committee on ethics and the informed consent of each patient, 30 ASA physical status 1 patients, ranging in age from 19 to $49 \mathrm{yr}$, scheduled for elective surgery (hysterectomy, tonsillectomy or osteosynthesis of the lower extremities) were randomly assigned to one of three groups. Ten patients inhaled $2.5 \%$ of isoflurane by a vaporizer (Isotec 5, Ohmeda) (Iso $2.5 \%$ group); ten patients inhaled $5.0 \%$ of isoflurane by a vaporizer (Iso $5.0 \%$ group); and ten inhaled $5.0 \%$ of isoflurane by a vaporizer and also received fentanyl $\left(2 \mu \mathrm{g} \cdot \mathrm{kg}^{-1}\right) \dot{i}$ two minutes before commencement of isoflurane inhalation (Iso $5.0 \%+F$ group), respectively.

Preanaesthetic fasting was started $12 \mathrm{hr}$ before induction of anaesthesia and any fluid deficit secondary to fasting was replaced with $5 \%$ dextrose containing lactated Ringer's solution $\left(0.5 \mathrm{ml} \cdot \mathrm{kg}^{-1} \cdot \mathrm{hr}^{-1}\right.$ of fasting) from three hours before until induction of anaesthesia from a 20-gauge catheter. The infusion rate during the measurement was maintained at $10 \mathrm{ml} \cdot \mathrm{kg}^{-1} \cdot \mathrm{hr}^{-1}$ and any preanaesthetic medication, such as atropine or sedatives, was not administered before the patient was taken to the operating room. In the operating room, monitoring of the ECG and of haemoglobin oxygen saturation by pulse oximetry were maintained and continued throughout the study period. An automated arterial pressure monitor (Dinamap, Critikon) was fixed to the arm without an intravenous catheter.

When two successive readings of mean arterial pressure (MAP) varied less than $10 \%, 100 \%$ oxygen was delivered to all groups by face mask, and in the Iso $5.0 \%$ $+\mathrm{F}$ group, fentanyl $\left(2 \mu \mathrm{g} \cdot \mathrm{kg}^{-1} \dot{\nu}\right)$ was also administered. Two minutes later, anaesthesia was induced with thiamylal ( $4 \mathrm{mg} \cdot \mathrm{kg}^{-1} i$ ) and was followed by vecuronium $\left(0.1 \mathrm{mg} \cdot \mathrm{kg}^{-1} \dot{i}\right)$. The lungs were ventilated with $100 \%$ oxygen (fresh gas flow rate was $6 \mathrm{~L} \cdot \mathrm{min}^{-1}$ ) and $2.5 \%$ or $5.0 \%$ isoflurane (inspired) through the face mask connected to a semiclosed anaesthesia system. Ventilation with face mask was continued for five minutes.

After induction of anaesthesia, the end-tidal carbon dioxide tension and isoflurane concentration were monitored with an infrared carbon dioxide and anaesthetic gas monitor (5250 RGM, Ohmeda). Throughout the measurement, the end-tidal carbon dioxide tension was maintained between 30-35 mmHg. Recordings of heart rate (HR) (from the ECG) and MAP (from the automated arterial pressure monitor) were taken according to the following schedule: at two minutes before induction of anaesthesia (baseline); immediately before induction and at three and five minutes after induction. The tympanic temperature of each patient was also recorded at the end of the measurements (Quick thermo, Terumo).

Values expressed in the text are means \pm SEM. The statistical analysis was performed using the KruskalWallis test for characteristics among the groups, a paired $t$ test for the end-tidal isoflurane concentration of each group, a one-way ANOVA, followed by Scheffe's F test for repeated measurements of HR and MAP of each group, and a two-way ANOVA, followed by an unpaired $t$ test for HR, MAP, and the end-tidal isoflurane concentration among the groups, when appropriate. In all analyses, a value of $P<0.05$ was considered as statistically significant.

\section{Results}

Patients in the three groups were comparable with regard to sex, age, height, weight, and a tympanic temperature (Table I). No difference in the end-tidal isoflurane concentration ( $\mathrm{F}$ iso) after induction of anaesthesia was noted between the Iso $5.0 \%$ and the Iso $5.0 \%+F$ groups (Table II). At five minutes after induction of anaesthesia, the $\mathrm{F}$ iso values were as follows: 1.2 MAC (Iso $2.5 \%$ ) and $2.2 \sim 2.3 \mathrm{MAC}$ (Iso 5.0\%), respectively. In all groups, laryngospasm due to the high-dose isoflurane inhalation was not demonstrated during the measurements.

The HR in the Iso $2.5 \%$ group did not change compared with baseline ( $83.7 \pm 6.2 \mathrm{bpm})$. In contrast, in the Iso $5.0 \%$ group, $\mathrm{HR}$ increased at five minutes after induction (112.2 $\pm 7.8 \mathrm{bpm})$, compared with baseline (78.5 $\pm 3.7 \mathrm{bpm})(P<0.01)$ and with the Iso $2.5 \%$ group at the same time $(86.7 \pm 3.7 \mathrm{bpm})(P<0.05)$. In Iso $5.0 \%+F$ group, no HR change was noted compared with baseline $(80.4 \pm 3.8 \mathrm{bpm})$, but an attenuation occurred at three minutes after induction $(81.9 \pm 4.1$ bpm) $(P<0.05)$, at five minutes after induction $(81.7$ $\pm 7.1 \mathrm{bpm})(P<0.01)$, compared with the Iso $5.0 \%$ 
TABLE I Patient characteristics

\begin{tabular}{llllll}
\hline Group & $\begin{array}{l}\text { Sex } \\
(M / F)\end{array}$ & $\begin{array}{l}\text { Age } \\
(y r)\end{array}$ & $\begin{array}{l}\text { Height } \\
(\mathrm{cm})\end{array}$ & $\begin{array}{l}\text { Weight } \\
(\mathrm{kg})\end{array}$ & $\begin{array}{l}\text { BT } \\
\mathrm{\rho C})\end{array}$ \\
\hline Iso $2.5 \%$ & $2 / 8$ & $38.4 \pm 2.8$ & $159.6 \pm 2.7$ & $53.9 \pm 2.6$ & $36.3 \pm 0.2$ \\
Iso $5.0 \%$ & $1 / 9$ & $36.5 \pm 2.9$ & $159.2 \pm 3.1$ & $58.1 \pm 2.6$ & $36.0 \pm 0.2$ \\
Iso $5.0 \%+\mathrm{F}$ & $3 / 7$ & $40.3 \pm 3.1$ & $160.8 \pm 2.5$ & $59.6 \pm 2.9$ & $36.3 \pm 0.1$ \\
\hline
\end{tabular}

Values expressed are means \pm SEM. Iso $2.5 \%=$ Iso $2.5 \%$ group (inhaled $2.5 \%$ isoflurane); Iso $5.0 \%=$ Iso $5.0 \%$ group (inhaled $5.0 \%$ isoflurane); Iso $5.0 \%+\mathrm{F}=$ Iso $5.0 \%+\mathrm{F}$ group (inhaled $5.0 \%$ isoflurane and also received $2 \mu \mathrm{g} \cdot \mathrm{kg}^{-1}$ fentanyl $i v$ two minutes before commencement of isoflurane inhalation; $\mathrm{BT}=\mathrm{a}$ tympanic temperature.

TABLE II End-tidal isoflurane concentration (\%) for each group

\begin{tabular}{lll}
\hline Group & $3 \min$ & $5 \min$ \\
\hline Iso $2.5 \%$ & $1.17 \pm 0.63$ & $1.35 \pm 0.05$ \\
Iso $5.0 \%$ & $2.15 \pm 0.14$ & $2.50 \pm 0.1$ \\
Iso $5.0 \%+\mathrm{F}$ & $2.29 \pm 0.09$ & $2.71 \pm 0.11^{*}$ \\
\hline
\end{tabular}

Values expressed are means \pm SEM. Three and five minutes after induction. Differences within each group from three minutes values; ${ }^{*} P$ $<0.05$; as determined by a paired $t$ test. Differences among the groups as determined by a two-way ANOVA.

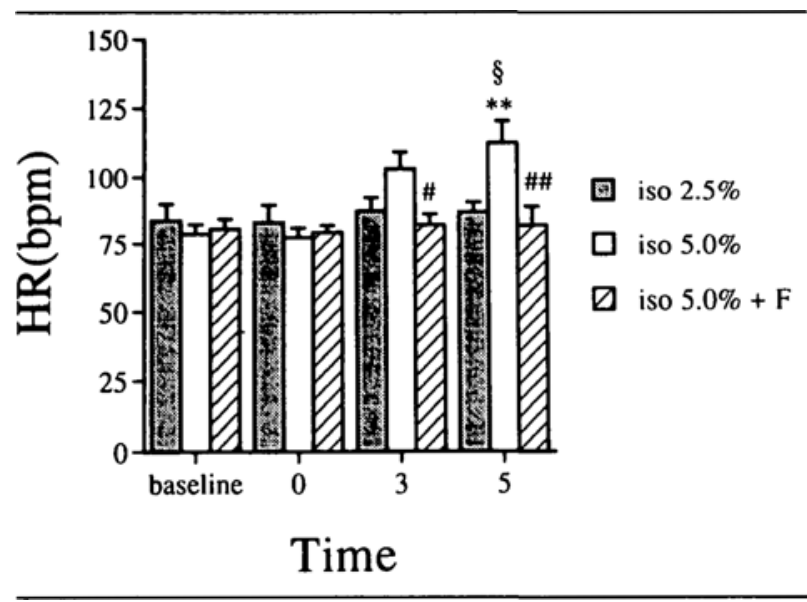

FIGURE 1 Heart rate (HR) during inhalation of $2.5 \%$ and $5.0 \%$ isoflurane and the effect of fentanyl pretreatment. Baseline, $0 \mathrm{~min}, 3$ $\mathrm{min}$ and $\mathrm{S}$ min represent two minutes before induction of anaesthesia, immediately before and at three and five minutes after induction of anaesthesia, respectively. Means \pm SEM. Differences within each group from baseline were significant at the following $P$ value; ${ }^{* *} P<$ 0.01 as determined by a one-way ANOVA followed by Scheffe's $F$ test. Differences among the groups were significant at the following $P$ values: $\S P<0.05$ (compared with Iso $2.5 \%$ group), \#P<0.05, \#\# $P$ $<0.01$ (compared with Iso $5.0 \%$ group), as determined by a two-way ANOVA followed by an unpaired $t$ test.

group at the same time $(102.9 \pm 6.2,112.2 \pm 7.8 \mathrm{bpm}$, respectively) (Figure 1).

The MAP in the Iso $2.5 \%$ group did not change compared with baseline $(86.6 \pm 3.3 \mathrm{mmHg})$. In the Iso $5.0 \%$ group, MAP did not change compared with baseline $(87.8$

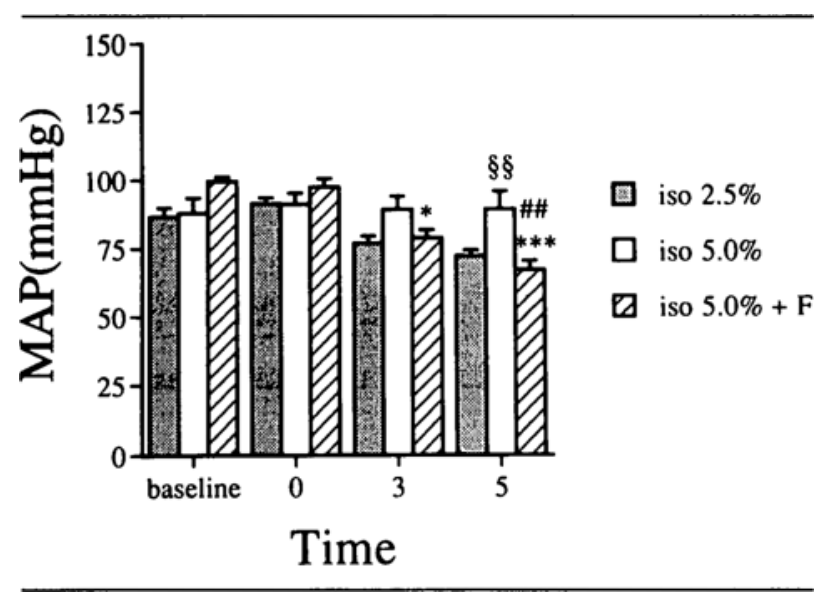

FIGURE 2 Mean arterial pressure (MAP) during inhalation of $2.5 \%$ and $5.0 \%$ isoflurane and the effect of fentanyl pretreatment. Differences within each group from baseline; $* P<0.05,{ }^{* * *} P<0.001$ as determined by a one-way ANOVA followed by Scheffe's $F$ test. Differences among the groups; $\S \S P<0.01$ (compared with Iso $2.5 \%$ group), \#\# $P<0.01$ (compared with Iso $5.0 \%$ group), as determined by a two-way ANOVA followed by an unpaired $t$ test.

$\pm 5.6 \mathrm{mmHg}$ ), but there was an increase at five minutes after induction $(89.0 \pm 6.7 \mathrm{mmHg}$ ) compared with the Iso $2.5 \%$ group at the same time $(72.1 \pm 2.1 \mathrm{mmHg})$ $(P<0.01)$. In contrast, in the Iso $5.0 \%+F$ group, MAP decreased at three minutes after induction (78.5 $\pm 3.0 \mathrm{mmHg})(P<0.05)$ and at five minutes after induction $(67.0 \pm 3.4 \mathrm{mmHg})(P<0.001)$, compared with baseline $(99.4 \pm 1.6 \mathrm{mmHg})$. Further, MAP at five $\mathrm{min}-$ utes after induction decreased compared with the Iso $5.0 \%$ group at the same time $(89.0 \pm 6.7 \mathrm{mmHg})(P$ $<0.01$ ) (Figure 2).

\section{Discussion}

This study found that inhalation of $5.0 \%$ isoflurane during induction of anaesthesia caused an increase in HR, compared both with baseline and with the results during $2.5 \%$ isoflurane inhalation. Also, $5 \%$ isoflurane caused an increase in MAP compared with $2.5 \%$ isoflurane inhalation. However, $2.5 \%$ isoflurane inhalation altered nei- 
ther HR nor MAP, compared with baseline values. Pretreatment with fentanyl attenuated this increase compared to those who had undergone $5.0 \%$ isoflurane inhalation.

We have shown that $5 \%$, but not $2.5 \%$ isoflurane, elicits a sympathetic response manifested by an increase in HR and MAP. Some studies also indicated that abrupt exposure to a high concentration of isoflurane, i.e., 5.0\%, caused an increase in both HR and MAP values ${ }^{1,4}$ but responses to lower concentrations of isoflurane did not augment HR and MAP. Yli-Hankala et al. ${ }^{4}$ found a response when the isoflurane concentration increased from $2.5 \%$ to $5.0 \%$. Ishikawa et al. ${ }^{1}$ also found that induction with $5 \%$ isoflurane increased HR and MAP, but, using a lower concentration (3\%), Randell et al. ${ }^{3}$ found only an increase in HR. Induction of anaesthesia in children with $3.75 \%$ isoflurane elicited an increase in both HR and systolic arterial pressure:

In contrast, our data shows that with $5 \%$ isoflurane inhalation the MAP value at five minutes is not different from baseline. The study by Yli-Hankala et al. ${ }^{4}$ showed that, although a sudden increase in isoflurane concentration during stable background anaesthetic did produce an increase in HR and in arterial pressure, this effect was transient, peaking at two minutes. Further, in Ishikawa's study, ${ }^{1}$ the effect occurred in approximately $30 \mathrm{sec}$. These are quite different from the present study when the conditions were constantly changing. Thus, our data may reflect the effect of co-induction with a barbiturate.

It has been reported that fentanyl, a commonly used opioid during anaesthesia, exerts its vagotonic action ${ }^{6}$ at the medulla oblongata. ${ }^{7}$ Flacke et al ${ }^{8,9}$ noted that in dogs during enflurane inhalation 50 or $100 \mu \mathrm{g} \cdot \mathrm{kg}^{-1}$ fentanyl $i v$ decreased plasma catecholamine concentrations. Further, Macnab et al. ${ }^{10}$ reported that during 2-2.5\% of isoflurane-induced hypotension for cerebral aneurysm surgery, 3-5 $\mu \mathrm{g} \cdot \mathrm{kg}^{-1}$ fentanyl $i v$ immediately before beginning of the surgery did not result in an increase in the plasma norepinephrine concentration. Moreover, Cahalan et al. "found that during $1 \%$ isoflurane inhalation, $1 \mu \mathrm{g} \cdot \mathrm{kg}^{-1}$ fentanyl $i v$ ten minutes after skin incision decreased both HR and MAP, compared with HR and MAP immediately before the fentanyl administration. Therefore, we hypothesized that pretreatment with fentanyl would attenuate HR and MAP enhancement during isoflurane inhalation. Based on our results that fentanyl decreased the enhancement of HR and MAP during $5.0 \%$ isoflurane inhalation, it is likely that fentanyl increases vagal activity. Further, it suggests that fentanyl attenuates the perception of the pungency of isoflurane and that attenuation also might account for the decreased response. On the other hand, fentanyl may attenuate circulatory responses during high concentration of isoflurane inhalation by decreasing plasma catecholamine con- centration. In Flacke's study, ${ }^{8,9}$ the fentanyl doses administered to achieve the decrease of the plasma catecholamine concentrations were much larger than that we administered. Thus, it is unlikely that fentanyl attenuates these circulatory responses via inhibition of the release of catecholamine. Moreover, in Macnab's study, ${ }^{10}$ the inhaled isoflurane concentration was lower than that in the present study. Thus, direct comparison between Macnab's study and ours may be difficult.

During normal anaesthesia, it is seldom necessary to increase the concentration of isoflurane so abruptly as in this study which might explain why the phenomenon during high concentration of isoflurane inhalation is rarely seen in clinical practice, particularly as most clinicians routinely administer a small dose of fentanyl or other opioid prior to induction of anaesthesia. Ishikawa et al. ' showed that increases in HR and MAP during inhalation of high concentrations of isoflurane were more marked in hypertensive patients. Therefore, particularly for hypertensive patients, fentanyl pretreatment prior to isoflurane inhalation may be more important than in normotensive patients.

It is concluded that a small amount of fentanyl possesses a prophylactic effect on the enhancement of HR and MAP of adult patients during inhalation of high concentrations of isoflurane. Further, we also have shown that $5 \%$, but not $2.5 \%$ isoflurane, elicits a sympathetic response manifested by an increase in HR and MAP. Thus, the increased HR and MAP during isoflurane inhalation might be avoided by limiting the concentration of isoflurane at induction of anaesthesia to $2.5 \%$.

\section{Acknowledgements}

We wish to thank Takefumi Sakabe MD, in the department of Anesthesiology-Resuscitology, Yamaguchi University school of medicine, for his valuable advice; Shigeki Yamashita MD, Hiroko Ogasahara MD, Naoki Masuda MD, Shiro Kojima MD, Hideo Oka MD, Yuji Miyata MD in the department of Anesthesia, Kurashiki Central Hospital, for their cooperation during the performance of this study.

\section{References}

1 Ishikawa $T$, Nishino T, Hiraga $K$. Immediate responses of arterial blood pressure and heart rate to sudden inhalation of high concentrations of isoflurane in normotensive and hypertensive patients. Anesth Analg 1993; 77: 1022-5.

2 Lindgren $L$, Randell T, Saarnivaara $L$. Comparison of inhalation induction with isoflurane or halothane in children. Eur J Anaesthesiol 1991; 8: 33-7.

3 Randell $T$, Seppälä $T$, Lindgren $L$. Isoflurane in nitrous oxide and oxygen increases plasma concentrations of no- 
radrenaline but attenuates the pressor response to intubation. Acta Anaesthesiol Scand 1991; 35: 600-5.

4 Yli-Hankala A, Randell T, Seppälä T, Lindgren L. Increases in hemodynamic variables and catecholamine levels after rapid increase in isoflurane concentration. Anesthesiology 1993; 78: 266-71.

5 Nishino T, Tanaka A, Ishikawa T, Hiraga K. Respiratory, laryngeal, and tracheal responses to nasal insufflation of volatile anesthetics in anesthetized humans. Anesthesiology 1991; 75: 441-4.

6 Reitan JA, Stengert KB, Wymore ML, Martucci RW. Central vagal control of fentanyl-induced bradycardia during halothane anesthesia. Anesth Analg 1978; 57: 31-6.

7 Laubie $M$, Schmitt $H$, Vincent $M$. Vagal bradycardia produced by microinjections of morphine-like drugs into the nucleus ambiguus in anaesthetized dogs. Eur $\mathrm{J}$ Pharmacol 1979; 59: 287-91.

8 Flacke JW, Davis LJ, Flacke WE, Bloor BC, Van Etten $A P$. Effect of fentanyl and diazepam in dogs deprived of autonomic tone. Anesth Analg 1985; 64: 1053-9.

9 Flacke JW, Flacke $W E$, Bloor BC, Olewine $S$. Effects of fentanyl, naloxone, and clonidine on hemodynamics and plasma catecholamine levels in dogs. Anesth Analg 1983; 62: 305-13.

10 Macnab MSP, Manninen PH, Lam AM, Gelb AW. The stress response to induced hypotension for cerebral aneurysm surgery; a comparison of two hypotensive techniques. Can J Anaesth 1988; 35: 111-5.

11 Cahalan MK, Lurz FW, Eger EI II, Schwartz LA, Beaupre PN, Smith JS. Narcotics decrease heart rate during inhalational anesthesia. Anesth Analg 1987; 66: 166-70. 